AperTO - Archivio Istituzionale Open Access dell'Università di Torino

\title{
"To Be or Not to Be in a Good Shape": Diagnostic and Clinical Value of Nuclear Shape Irregularities in Thyroid and Breast Cancer
}

\section{This is the author's manuscript}

Original Citation:

\section{Availability:}

This version is available http://hdl.handle.net/2318/143502

since

Publisher:

Springer Science+Business Media

Published version:

DOI:10.1007/978-1-4899-8032-8_5

Terms of use:

Open Access

Anyone can freely access the full text of works made available as "Open Access". Works made available under a Creative Commons license can be used according to the terms and conditions of said license. Use of all other works requires consent of the right holder (author or publisher) if not exempted from copyright protection by the applicable law. 


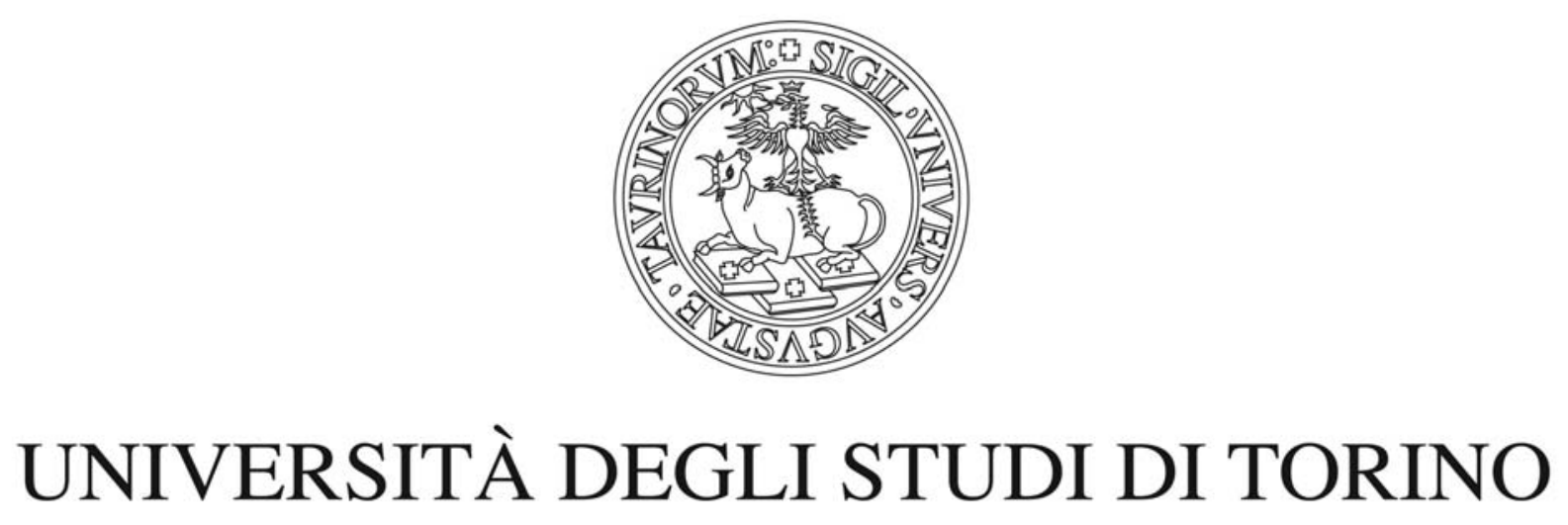

Thisis an author version of the contribution published on:

Questa è la versione dell'autore dell'opera:

ADVANCES IN EXPERIMENTAL MEDICINE AND BIOLOGY, 773, XIII, 2014, ADVANCES IN EXPERIMENTAL MEDICINE AND BIOLOGY

The definitive version is availableat:

La versione definitiva è disponibile alla URL:

http://link.springer.com/chapter/10.1007\%2F978-1-4899-8032-8 5 


\title{
"To Be or Not to Be in a Good Shape": Diagnostic and Clinical Value of Nuclear Shape Irregularities in Thyroid and Breast Cancer
}

\author{
Gianni Bussolati , Francesca Maletta , Sofi a Asioli , Laura Annaratone , Anna Sapino , and \\ Caterina Marchiò \\ University of Turin, Italy
}

\begin{abstract}
Variation in both nuclear shape and size ("pleomorphism"), coupled with changes in chromatin amount and distribution, remains the basic criteria for microscopy in a cytologic diagnosis of cancer. The biological determinants of nuclear shape irregularities are not clarifi ed, so, rather than on the genesis of nuclear irregularities, we here focus our attention on a descriptive analysis of nuclear pleomorphism.

We keep in mind that evaluation of nuclear shape as currently practiced in routine preparations is improper because it is indirectly based on the distribution of DNA as revealed by the affi nity for basic dyes. Therefore, over the last years we have been using as criteria morphological features of nuclei of thyroid and breast carcinomas as determined by immunofl uorescence, in situ hybridization, and $3 \mathrm{D}$ reconstruction. We have translated this approach to routine diagnostic pathology on tissue sections by employing immunoperoxidase staining for emerin. Direct detection of nuclear envelope irregularities by tagging nuclear membrane proteins such as lamin B and emerin has resulted in a more objective defi nition of the shape of the nucleus. In this review we discuss in detail methodological issues as well as diagnostic and prognostic implications provided by decoration/staining of the nuclear envelope in both thyroid and breast cancer, thus demonstrating how much it matters "to be in the right shape" when dealing with pathological diagnosis of cancer.
\end{abstract}

Keywords Nuclei $・$ Pleomorphism $・$ Papillary carcinoma $・$ Breast cancer $・ 3 D$

\section{Abbreviations}

FISH Fluorescence in situ hybridization

H\&E Hematoxylin and eosin

NE Nuclear envelope

PTC Papillary thyroid carcinoma

PDC Poorly differentiated carcinoma

NEP Nuclear envelope pleomorphism 


\section{Introduction}

Irregularity of nuclear shape and an increased nuclear-cytoplasmic ratio (also called karyoplasmic ratio) characterize most, though not all, neoplastic conditions. In fact, we can roughly consider, as far as nuclear shape in cancer is concerned, three types of events. In some tumors, nuclei are roundish, with a smooth nuclear membrane not dissimilar from the corresponding normal epithelium. However, in the vast majority of cancers most nuclei are pleomorphic, as defi ned by the presence of irregularities in both nuclear shape and size coupled with changes in chromatin amount and distribution within the nucleus [ 1 ]. Such features remain the basic microscopy criteria for a cytologic diagnosis of cancer: indeed, indentations, undulations, and folds of the nuclear membrane, as originally reported by ultrastructural observations [ 2 ], occur early in neoplastic processes [ 3 ].

Finally, in some types of cancer, and notably in thyroid cancer, nuclear shape irregularity presents a typical and reproducible pattern, acquiring clear diagnostic significance. Typically, papillary thyroid carcinoma (PTC) is characterized by the presence of indentations, grooves (the so-called coffee-bean nuclei), pseudo- inclusions (or "Orphan-Annie-eyed" nuclei), and nuclear clearing. These characteristics derive from fi nely dispersed chromatin or deep and complex cytoplasmic longitudinal invaginations into the double-membrane nuclear envelope (NE), as demonstrated by electron microscopy [ $4-7$ ]. The presence of these features is the only clue to the diagnosis of PTC, which alone represents almost $80 \%$ of all thyroid carcinomas [ 8 ].

The Nuclear Envelope and Rationale for Its Use in Pathology Light microscopy appreciation of nuclear pleomorphism in cytopathology and histopathology is indirect, as it is currently based on staining of nucleic acids with basic dyes such as hematoxylin. Since peripheral chromatin is bound to the nuclear membrane, this provides crude evidence of nuclear shape. However, a method to decorate the NE could provide direct detection of the NE and its components.

Indeed, by highlighting NE-associated proteins we could provide a more objective and direct appreciation of nuclear shape and defi nitively reconstruct nuclear shape based on the distribution of NE proteins [ 1 ].

Detection, appreciation, and rendering of nuclear shape are, for intrinsic reasons, different in cytopathology and in histopathology. In fact, while in the cytological approach whole nuclei are available for investigations, in histological sections only nuclear segments are available, which makes images partial and seldom conclusive.

Moreover, in diagnostic cytology, the preservation of nuclear shape is heavily infl uenced by the technical procedure for preparations, since in liquid cytology, the shape of the nucleus is fully preserved. By contrast, smearing followed by cell drying is bound to produce a collapse of the nuclear shape leading to misdiagnosis.

With these caveats in mind, the following approaches have been followed by our group: A. Tagging of components of the nuclear membrane by immunofl uorescence and immunoperoxidase staining (Figs. 1, 2, and 3 ) B. Immunofl uorescence decoration of the nuclear membrane, associated with gene labeling by $\mathrm{fl}$ uorescence in situ hybridization (FISH) (Fig. 4 ) C. Confocal microscopy and image capture, followed by 3D reconstruction using specifi c software (e.g. Amira 3D Analysis Software for Life Sciences- http://www.vsg3d.com/ ) (Figs. 4 , 5 , and 6 ) D. Image analysis using specifi c softwares (e.g. Image-Pro Plus, MediaCybernetics, http://www.mediacy.com , which is an image analysis software package for fl uorescence imaging and for recording sequential images). 
Following these procedures, we have been able to trace the distribution of the NE with immunofl uorescence and immunoperoxidase procedures by using antibodies targeting lamin $B$ and another NE marker, namely, emerin [ 9 ] (approaches A, B).

These two proteins label different structural components, since lamin B is located in the proteinaceous layer at the interface between the chromatin and the membrane, while emerin is a transmembrane protein of the inner nuclear membrane [ 9 ]. We also obtained a proper 3D reconstruction of the nuclear shape (approaches $B, C$ ).

Confocal microscopy analysis allows the creation of a stack of images along the z-axis that can be uploaded into dedicated software for advanced 3D visualization and volume modeling. The nuclear outline is obtained after segmentation of sequential images of nuclear sections [ 10 ]. The segmented areas are then employed to generate 3D polygonal surface models using macros in the dedicated software (approaches A, B, C). An alternative procedure to confocal microscopy for generating sharp images from tissue specimens is provided by deconvolution technology (approach D). Briefl y, immunofl uorescent preparations are examined typically with a wide-fi eld fl uorescence microscope, equipped with either a motorized stage or a piezo focus lens positioner, a camera, and a dedicated software that allows 3D image stacks to be recorded. Subsequent deconvolution of the image stacks improves the clarity of images by applying an algorithm that uses pixel information in the adjacent sections to remove out-of-focus light [ 11, 12 ]. With confocal microscopy a single nucleus can be observed at different and sequential cutting planes, and a 3D

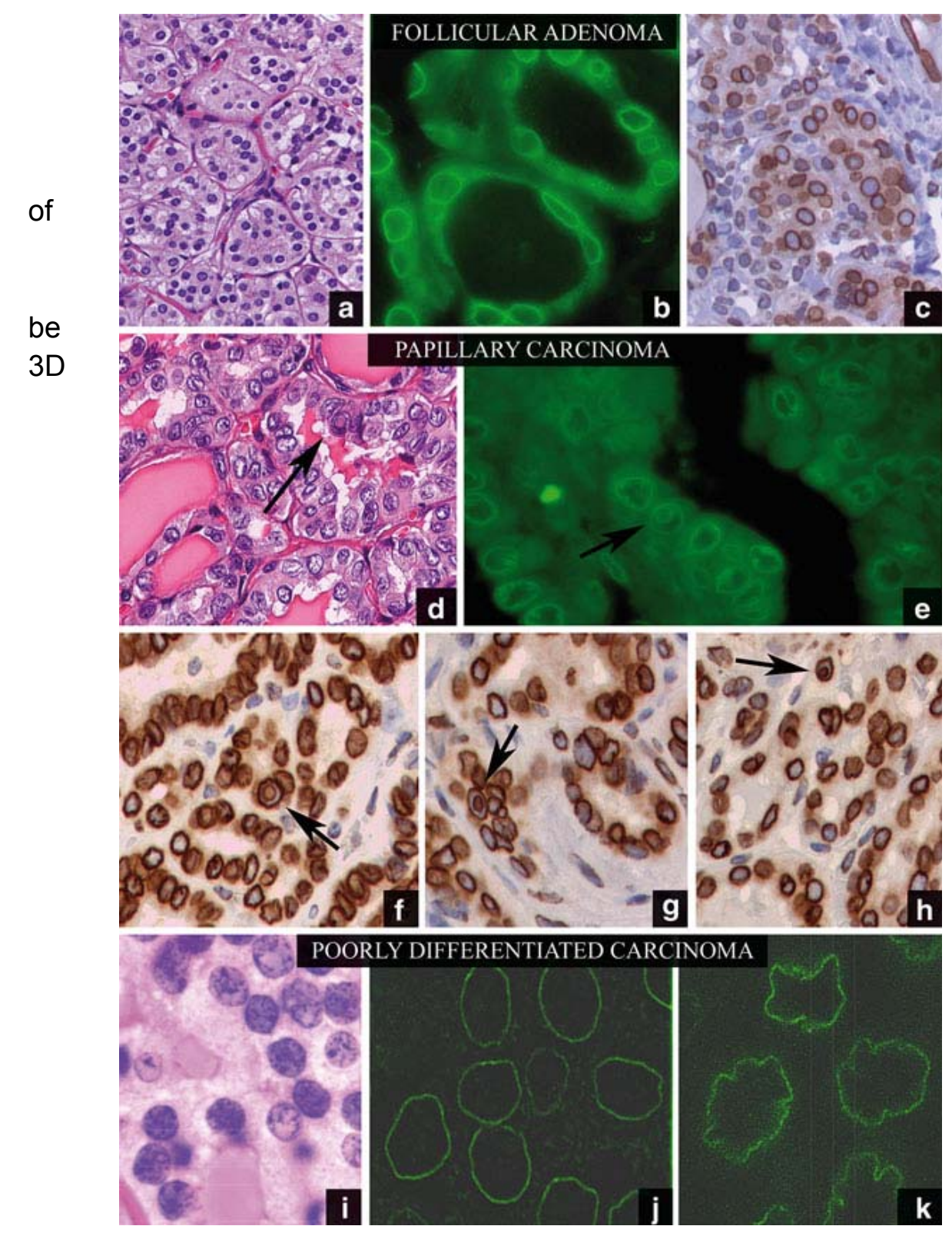
reconstruction can be obtained by adding each section to build up the entire nuclear volume. Similarly, after removal the out-offocus light by deconvolution, the individual sections can reconstructed to obtain models. 
Fig. 1 How emerin staining in both immunofl uorescence and immunoperoxidase highlights nuclear shape in a spectrum of thyroid lesions. Panels $(\mathrm{a}-\mathrm{c}$ ) are a follicular adenoma stained in various ways. The presence of round and regular nuclei is evident. Parallel sections were stained with ( a ) hematoxylin and eosin (H\&E), ( b ) immunofl uorescence for emerin, and ( c ) immunoperoxidase for emerin. Panels $(d-h)$ are an example of papillary thyroid carcinoma showing NE irregularities. ( d ) An H\&Estained section of a thyroid proliferation with irregular nuclei and scarce pseudo-inclusions ( arrow ). ( e ) The irregularities become extremely evident with immunofl uorescence for emerin. ( $f-h$ ) Similarly immunoperoxidase staining for emerin reveals the presence of several pseudo-inclusions by marking nuclear shape and highlighting its foldings ( arrows in $\mathrm{e}-\mathrm{h}$ : evident and widespread nuclear pseudoinclusions). Panels ( $\mathrm{i}-\mathrm{k}$ ) are a case of poorly differentiated carcinoma. ( i ) H\&E staining reveals nuclei to look quite regular with only scarce irregularities of the nuclear contours. ( $j$ ) Immunofl uorescence staining for emerin reveals nuclei that can look quite regular (as in follicular lesions). ( k ) However, in some cells this staining reveals the so-called star-shaped or raisin-like features

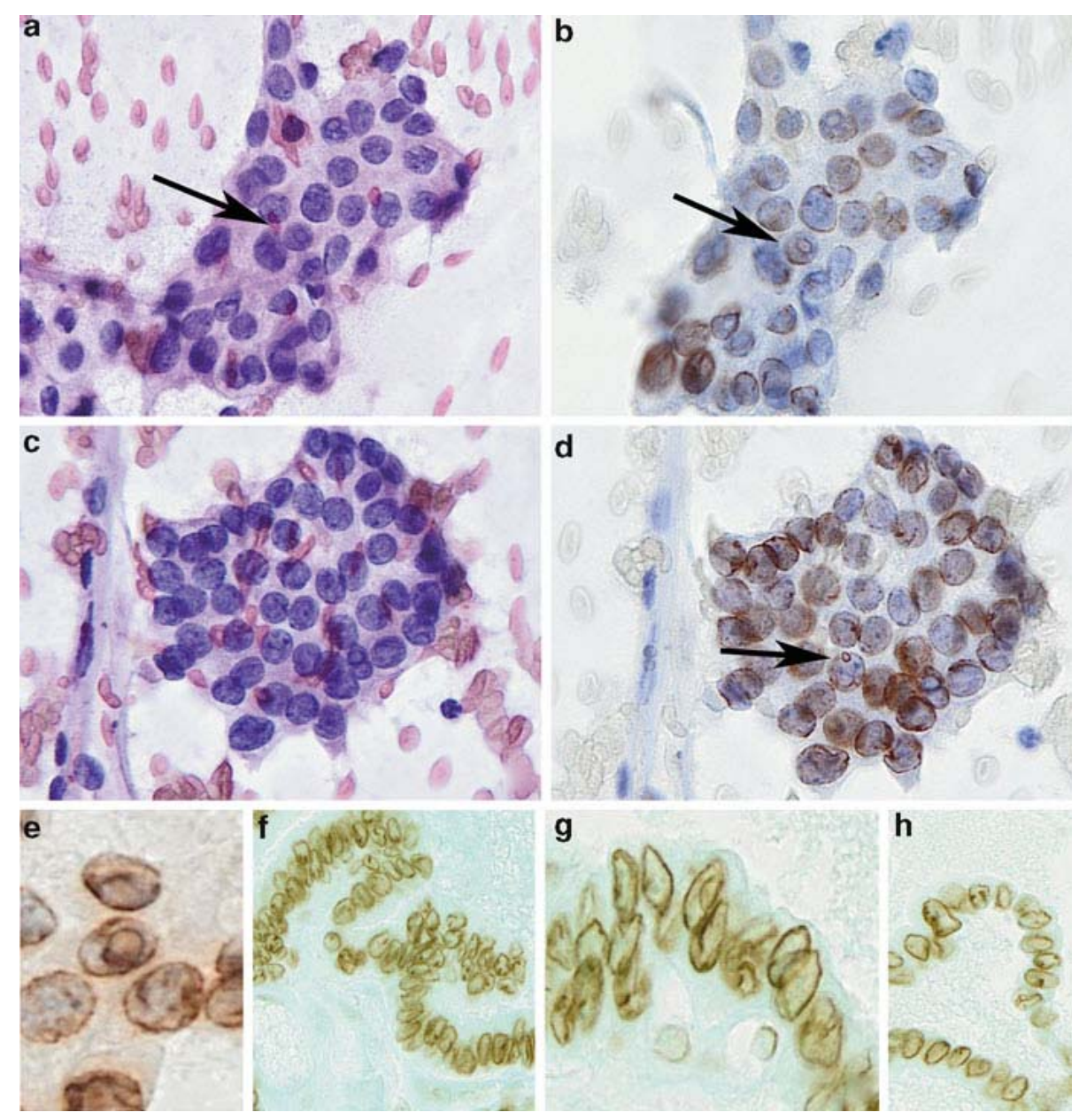

Fig. 2 Emerin staining in cytological specimens of papillary thyroid carcinoma. ( a - d ) Cases of papillary thyroid carcinoma (PTC) in alcohol-fi xed smears, ( e ) with Thin Prep, and panels ( $f-h$ ) are cell blocks obtained from fi ne needle aspirations on thyroid nodules. In smears ( $a, c$ ) cells are stained with hematoxylin and eosin (H\&E), while ( $b$, d) are the same fi elds and nuclei stained with immunoperoxidase for emerin. Direct comparison of the same fi elds reveals the superior ability of emerin staining to highlight diagnostic nuclear features, such as nuclear pseudo-inclusions (arrows in a , b ), even of very small size ( arrow in d), grooves, and crescent-like fi gures. ( e ) On Thin Prep preparations, pseudo-inclusions are evident. $(f-h)$ The emerin-stained sections obtained from cell block highlight other features typical of PTC, such as the garland-like appearance $(f)$ and deep irregularities of nuclear shape $(g, h)$ 



Fig. 3 Micrographs depicting different scenarios in the evaluation of nuclear pleomorphism in breast cancer pathology. Ductal carcinoma in situ (DCIS) of low nuclear grade ( $a, b)$ shows a regular lining of the nuclear envelope by immunofl uorescence for emerin ( b ). ( c , d ) Immunofl uorescence for emerin best shows fi ne irregularities of the nuclei in ductal carcinoma in situ of high nuclear grade. ( $\mathrm{e}, \mathrm{f}$ ) Finally, an example of infi Itrating ductal carcinoma (IDC) of low histological grade shows high-grade nuclear envelope pleomorphism (NEP), as best highlighted by immunofl uorescence for emerin 

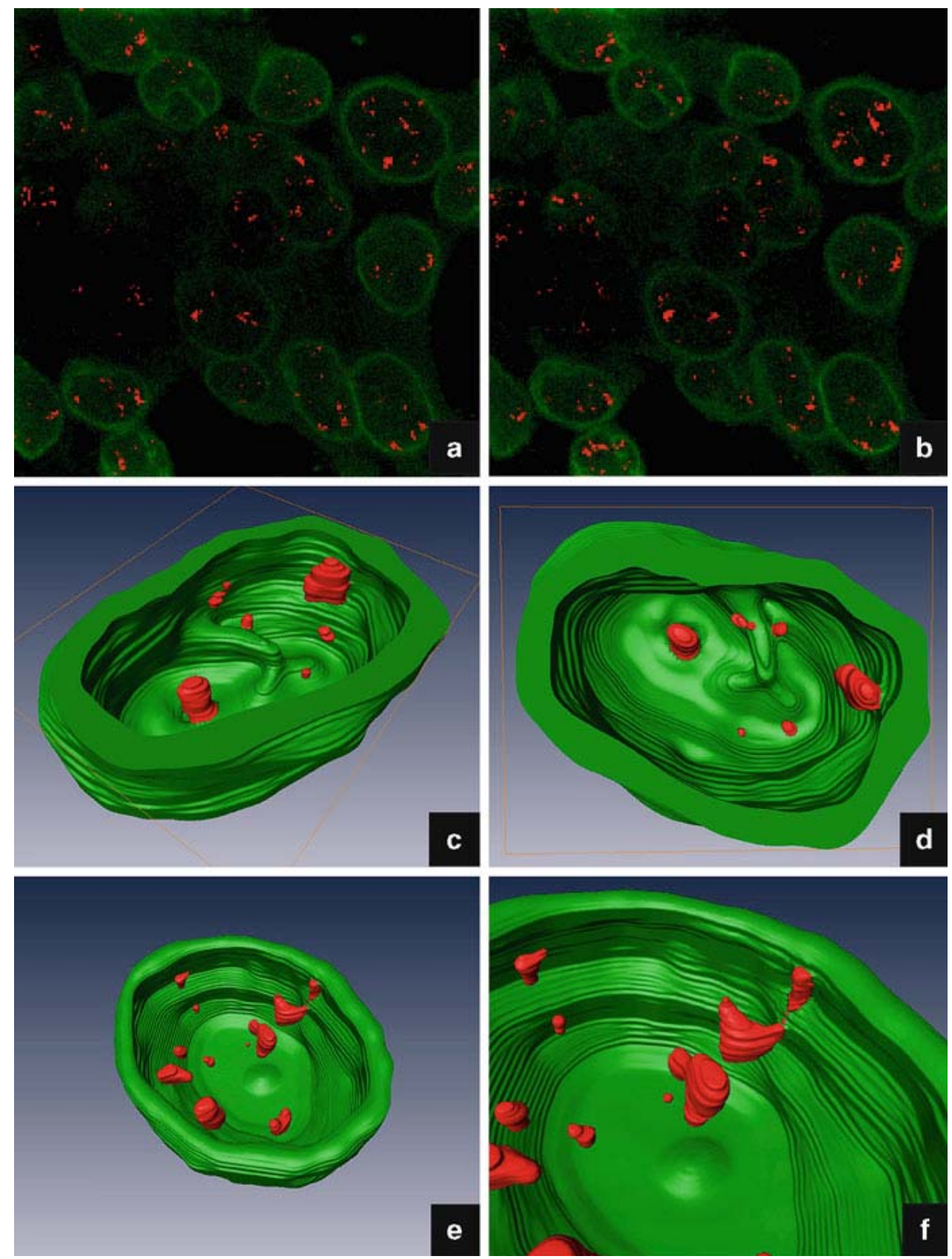

Fig. 4 3D reconstruction of nuclei with visualization of HER2 gene. ( a , b ) Immunofl uorescence for lamin B ( green ) is performed together with fluorescence in situ hybridization (FISH) for the HER2 gene ( red signals) in BT-474 cells ( HER2 amplifi ed, as exemplifi ed by the gene clusters). ( $c-f$ ) 3D reconstruction of these nuclei shows the relationship between HER2 gene clusters and nuclear envelope 

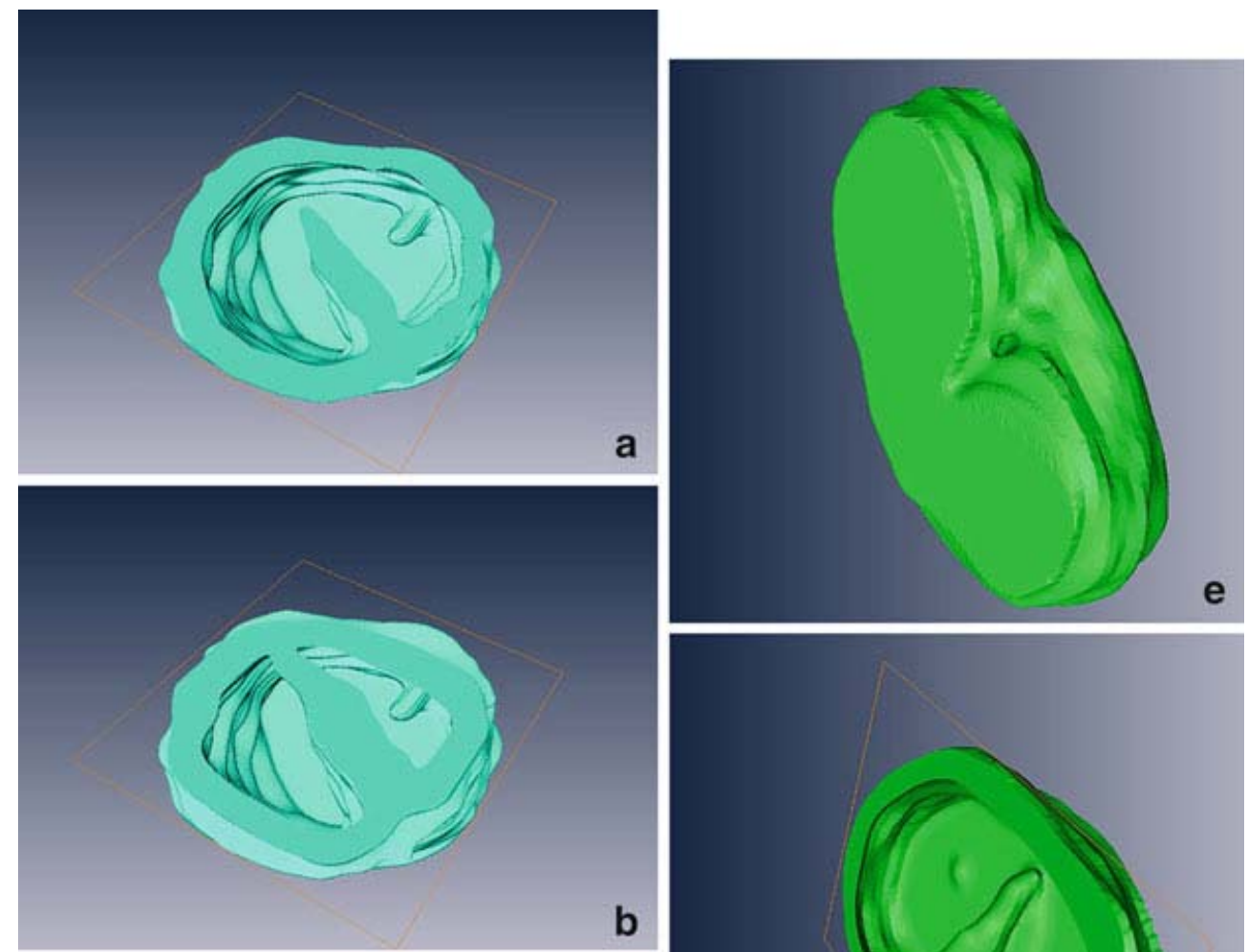

b


d

Fig. 5 3D reconstruction of PTC nuclei. Panels $(\mathrm{a}-\mathrm{d}$ ) are images obtained from sequential cutting planes of a single papillary thyroid carcinoma (PTC) nucleus, while images from ( $\mathrm{e}-\mathrm{g}$ ) are different perspectives of a 3D reconstruction of another example of PTC nucleus. Immunofl uorescence for emerin was performed on sequential sections of nuclei from PTC cell lines, and a 3D reconstruction was obtained using software Amira (Amira 3D Analysis Software for Life Sciences - http://www.vsg3d.com). The models of nuclear shape here shown revealed the presence of irregularities of the nuclear membrane with foldings and invaginations, which corresponds to the so-called coffee bean (or grooves) on traditional H\&E-stained nuclei 

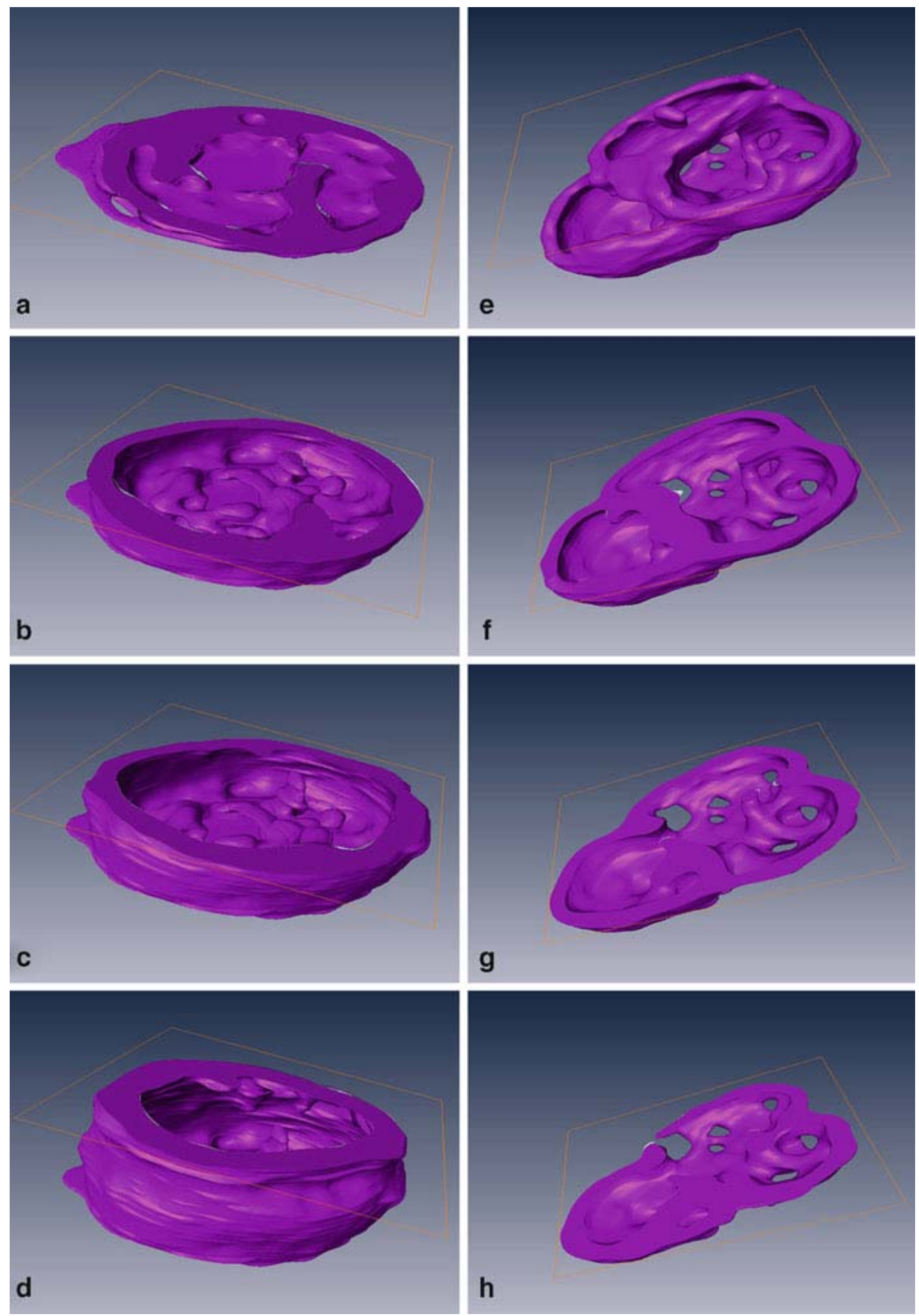

Fig. 6 3D reconstruction of breast cancer nuclei. Panels $(a-d)$ and $(e-h)$ are images obtained from sequential cutting planes of two different nuclei of breast cancer. Immunofl uorescence for lamin B was performed on sequential sections of nuclei from breast cancer cells (BT-474). The software Amira (Amira 3D Analysis Software for Life Sciences-http://www.vsg3d.com) was used to obtain a 3D reconstruction. The 3D models highlight irregularities of nuclear contour and several intranuclear tubules 


\section{Diagnostic and Clinical Impact of Nuclear Shape in PTC}

Over the years, we have focused our attention on nuclear pleomorphisms and alterations in shape (dysmorphisms) that occur in cancers and specifi cally in thyroid and breast carcinomas, two areas in which nuclear pleomorphism holds high biological signifi cance and great diagnostic and prognostic impact. In breast carcinoma the nuclear shape varies according to the histological subtype and grade, involving also a prognostic significance. In thyroid carcinomas the nuclear shape is instead paradigmatic and diagnostic of specific types of cancer.

\section{Nuclear Shape in PTC and PDC Versus Other Thyroid Pathologies}

A study conducted on cell lines derived from PTC and from follicular carcinomas, as well as on histological sections and cytological fi ne needle aspiration samples, showed an intense and diffuse staining for lamin B along the nuclear membrane irrespective of the tumor type [ 10 ].

Remarkable nuclear deformities, infolding, and "tubelike" invaginations were evident in the vast majority of PTC nuclei, and the typical intranuclear pseudoinclusions were also lined by lamin B. Moreover, PTC nuclei were larger and much more irregular than the corresponding control cases of follicular tumors (Fig. 1 ). The invaginations and indentations of PTC nuclei, as revealed by the sequential reconstructions obtained with the use of the confocal microscope, appeared to penetrate into the nucleus to a variable degree from a minimal fraction up to reach an entire penetration, which, as a consequence, acquires a "donut-like" configuration. Serial sections showed that "pouches" or "tunnels" that were seen in 3D reconstructions (Fig. 5 ) corresponded to the pseudo-inclusions typical of PTC nuclei and appeared to be always connected to the cell cytoplasm and lined by intact nuclear membrane.

In control cases of follicular tumors, nuclei were smaller than in PTC, with a round or an oval shape and a regular and smooth contour. Confocal microscope and 3D-reconstruction images highlighted the presence of only slight and occasional deformities. It can be thus concluded that the typical irregularities of PTC nuclei may appear at the light microscopy level alternatively as grooves or pseudo-inclusions according to the viewpoint from which the cell is explored, but they are all facets of the same phenomenon of large-scale invaginations with reciprocal cytoplasm bulging.

Moreover, the study with confocal microscopy and 3D reconstructions acquired diagnostic usefulness, since it opened the possibility to apply knowledge on nuclear shape and volume to the so-called grey area of thyroid pathology, which comprises follicular patterned lesions with optically clear nuclei but without clear-cut features of PTC. Irregularly shaped nuclei in fact can also be found in thyroiditis, hyperplastic lesions, goiter with degenerative changes, oxyphilic tumors or be the consequence of the fi ne needle aspiration procedure or the fi xation artefacts [ 13 ].

These benign lesions may have nuclear irregularities that mimic those of PTC: besides clear nuclei, occasional grooves can be appreciated and widespread alterations of nuclear contour are often present. What distinguishes these lesions from PTC is a combination of several factors, both histological (architecture, presence of vascular and/or capsular invasion) and cytological (extent, frequency, and intensity of nuclear irregularities, presence of nuclear pseudo-inclusions), but traditional staining may not be sufficient to fully appreciate these differences and distinction may be challenging. For this reason, the use of immunohistochemical staining to improve detection of nuclear shape might be of help in this differential diagnosis.

In order to apply this method of nuclear stain to routine histological and cytological diagnosis, immunohistochemical staining with anti-emerin antibodies was evaluated [ $9,14,15]$. Emerin is a 
protein of the inner nuclear membrane which appears to interact with the lamina and chromatin; it is a serine-rich nuclear membrane protein involved in mediating membrane anchorage to the cytoskeleton [ 16 ]. Fischer et al. [ 17 ] demonstrated that its expression is not reduced or abolished in cytoplasmic pseudo-inclusions or grooves of PTC, but it simply conforms to nuclear irregularities and foldings. Thus, cases of PTC, follicular adenoma, follicular carcinoma, Hashimoto's thyroiditis, goiter, Graves disease, and normal thyroid tissues were stained with antiemerin antibodies.

In PTC, emerin staining allowed an easy identification of all previously described nuclear irregularities (invaginations, pseudo-inclusions, grooves, crescent-like nuclei, and deep-stellate nuclear shape) but also a peculiar pattern never described before, which is the presence of minute curls along the periphery of the nucleus, leading to a garland-like pattern (Figs. 1 and 2 ); moreover, when directly comparing the same nuclei stained with immunofl uorescence for emerin and subsequently restained with hematoxylin and eosin (H\&E), it was evident that only some of the grooves seen with immunofluorescence were appreciable with H\&E as well. For this reason, emerin staining was tested on cases of follicular variant of PTC (FVPTC). This controversial variant is in fact characterized by follicles lined by cells that lack the typical features of PTC: nuclei are dark, and irregularities of shape are often borderline. Grooves are scarce and pseudo-inclusions rare or totally absent [ $6,18,19$ ]. For this reason, the diagnosis of FVPTC is traditionally affected by a high rate of inter-observer discordance, even among the so-called expert thyroid pathologists [ $20-22$ ]. The distinction between FVPTC on one side and benign lesions on the other (follicular adenoma, goiter, nodule in the context of thyroiditis) is based on the shape of the nucleus, presenting grooves and invaginations in the former while roundish in the latter. The differential diagnosis is important since it carries a profound therapeutic and prognostic impact, but it is sometimes difficult and problematic, because of improper preservation of the nuclear shape in histological sections.

After emerin staining of cases of FVPTC, invaginations of the nuclear membrane were more evident than on H\&E slides, and emerin tracing of the envelope allowed the recognition of some pseudo-inclusions that were "hidden" by the presence of dark nuclei in H\&E preparations.

Staining for emerin shows distinct and different patterns between PTC nuclei and other conditions, because it reveals more clearly nuclear irregularities in cases of PTC, while it confirms a regular nuclear profile in normal thyroid gland and other lesions (follicular lesions, goiter, thyroiditis). In fact, we have demonstrated that in thyroid lesions other than PTC, the vast majority of cells have smooth and round nuclei and only occasional cells may have irregularities of shape and invaginations similar to PTC nuclei [ 9 ]. Of note, such irregularities are only occasional and never reach the degree so typical and diagnostic of PTC.

The diagnosis of poorly differentiated carcinoma (PDC) is based on a diagnostic algorithm involving the presence of a solid, trabecular, or insular histological pattern as well as of necrosis and increased rate of mitoses [ 23 ]. However, a role in the diagnosis is played by nuclei as well. In PDC, nuclei are small (if compared with PTC nuclei), round, and hyperchromatic and lack typical clear-cut features of PTC (pseudo-inclusions, grooves, crescent-like features). Nuclei in PDC appear as "convoluted" because of the presence of an irregular ("convoluted" or "raisin-like") contour membrane. Only occasional grooves are observed, and no ground-glass appearance or pseudo-inclusions. By decorating/staining the NE with anti-emerin antibodies, PDC-convoluted or raisin-like nuclei showed humps and plicae, thus giving the appearance of a star-shaped structure (Fig. 1 ). 


\section{Thyroid Cytology}

Tracing the nuclear membrane by emerin decoration/staining could improve the preoperative cytological diagnosis of thyroid carcinomas.

In particular, one of the main issues in thyroid cytopathology is the so-called indeterminate category, which includes cases where the lesion cannot be clearly defined as benign or malignant based on morphology alone; these cases are collectively grouped into the III and IV categories according to the Bethesda System for reporting Thyroid Cytopathology [ 24 ]. The categories III and IV (see Table 1a ) are considered a sort of "grey zone" of thyroid cytology, and several authors have discussed the issue of "indeterminate" thyroid fi ne needle aspiration diagnosis. Efforts to detect cytological features or ancillary procedures that could distinguish between benign and malignant follicular patterned lesions (in need of surgical removal) have been the subject of several studies, but none was found to have absolute value or reproducibility [ $25-31$ ].

Our results showed that emerin correctly traced the nuclear membrane in all types of cytological specimens (smear, cell block, Thin Prep) (see Table 1b ). Smears and Thin Preps from cases with a defi nite cytological diagnosis of malignancy (category VI according to Bethesda System) [ 24 ] showed evident nuclear irregularities with foldings, grooves, and pseudo-inclusions. Comparison on the same nuclei of the H\&E and immunoperoxidase slides (by recording H\&E cytological images, demounting, and then restaining for emerin) (Fig. 2 ) clearly demonstrates the increased ability to defi ne the nuclear membrane and its irregularities.

\section{Table 1}

\begin{tabular}{|c|c|c|c|}
\hline \multicolumn{4}{|c|}{$\begin{array}{l}\text { Categories for reporting thyroid cytopathology (Bethesda } \\
\text { System) (a) }\end{array}$} \\
\hline \multicolumn{3}{|r|}{ Categor } & Risk of \\
\hline I & \multicolumn{2}{|c|}{ Nondiagnostic or Unsatisfactory } & $1-$ \\
\hline II & \multicolumn{2}{|c|}{ Benign } & $\begin{array}{c}0- \\
3 \%\end{array}$ \\
\hline III & \multicolumn{2}{|c|}{$\begin{array}{l}\text { Atypia of Undetermined Significance or Follicular } \\
\text { Lesion of Unde-termined Significance }\end{array}$} & $\begin{array}{c}5- \\
15 \%\end{array}$ \\
\hline IV & \multicolumn{2}{|c|}{$\begin{array}{l}\text { Follicular Neoplasm or Suspicious for a Follicular } \\
\text { Neoplasm }\end{array}$} & $\begin{array}{c}15- \\
30 \%\end{array}$ \\
\hline V & \multicolumn{2}{|c|}{ Suspicious for Malignancy } & $60-$ \\
\hline VI & \multicolumn{2}{|c|}{ Malignant } & $\begin{array}{l}97- \\
99 \%\end{array}$ \\
\hline \multicolumn{4}{|c|}{ Cytology processing-tissue methods (b) } \\
\hline \multicolumn{2}{|c|}{ Smear } & \multicolumn{2}{|c|}{$\begin{array}{l}\text { Specimens from FNA are immediately spread thinly on a } \\
\text { microscope slide, air-dried or alcohol- fixed and stained } \\
\text { for examination. }\end{array}$} \\
\hline \multicolumn{2}{|c|}{ Thin Prep } & \multicolumn{2}{|c|}{$\begin{array}{l}\text { Specimens from FNA are put in a special fluid collection system } \\
\text { and the slides for cytologic examination are filtered out in one- } \\
\text { cell-thick layers on a slide. }\end{array}$} \\
\hline \multicolumn{4}{|c|}{$\begin{array}{l}\text { Cell-block Specimens from FNA are directly fixed in alcohol, } \\
\text { centrifugated, paraffin- embedded, thus obtaining cell-blocks } \\
\text { from which } 3-5 \mu \mathrm{m} \text { sections can be cut. }\end{array}$} \\
\hline
\end{tabular}

FNA $=$ fi ne needle aspiration

This approach proved particularly useful in the definition of unclear and problematic cases classified as III/IV categories: by highlighting and amplifying nuclear irregularities (e.g., invaginations, true inclusions, grooves), it helped in identifying, among all the indeterminate cases, the malignant lesions, which, after surgery, proved to be PTC or FVPTC. Those nuclear 
irregularities which were barely perceivable or borderline on H\&E preparations proved instead more evident with emerin staining, and this helped in raising the suspicion of a malignant lesion.

In conclusion, emerin staining proved a useful tool to correctly identify PTC nuclei and to discriminate FVPTC cases among lesions classified as III/IV categories according to the Bethesda System [ 24 ]. It can be performed on smears, even after H\&E staining, thus allowing for the accurate and straightforward identification of nuclear changes characteristic of PTC even in fi ne needle aspiration samples with very scant cellularity (number of cells obtained by FNA).

\section{Diagnostic and Clinical Impact of Nuclear Shape in Breast Cancer}

In breast cancer diagnostic pathology it is well known that irregularities in nuclear shape as observed by H\&E staining play a crucial role in the diagnosis of both in situ and infiltrative lesions. Indeed, in situ carcinomas are classified using a threetier system (Table 2 ) into low-, intermediate, and high-grade lesions based on the degree of nuclear pleomorphism. Nuclear pleomorphism represents one of just three components to be evaluated in the grading system of invasive breast carcinomas, the others being the number of mitoses and architectural growth pattern [ 32 ]. Histological grade (Table 2 ) holds a universally acknowledged robust prognostic value [ 32 ]; however, regrettably intra- and inter-pathologist agreement on grading in breast cancer is reported between poor and moderate [ 33,34 ]. Indeed, the interobserver agreement ranges between 50 and $85 \%$, and about $40-50 \%$ of breast cancers are diagnosed as grade 2 cancers [ 32,33 ].

Table 2 Schematic representation of how histological grade is performed in breast cancer diagnostic pathology

\begin{tabular}{|c|c|c|c|}
\hline $\begin{array}{l}\text { Growth } \\
\text { pattern }\end{array}$ & $\begin{array}{l}\text { Mitotic count* } \\
\text { (applied to } \\
\text { HPF diameter }\end{array}$ & Nuclear pl & omorphism \\
\hline $\begin{array}{l}>75 \% \text { of } \\
\text { tubule } \\
\text { formation } \\
\text { SCORE } 1\end{array}$ & $\begin{array}{l}\text { 1-4 mitoses } \\
\text { SCORE } 1\end{array}$ & $\begin{array}{l}\text { Small and } \\
\text { roundish nuclei } \\
\text { with uniform } \\
\text { chromatin } \\
\text { SCORE } 1\end{array}$ & \\
\hline $\begin{array}{l}10-75 \% \text { of } \\
\text { tubule } \\
\text { formation } \\
\text { SCORE } 2\end{array}$ & $\begin{array}{l}\text { 5-11 mitoses } \\
\text { SCORE } 2\end{array}$ & $\begin{array}{c}\text { Variable shape and } \\
\text { size, vescicolous } \\
\text { chromatin, nucleoli } \\
\text { present } \\
\text { SCORE } 2\end{array}$ & \\
\hline $\begin{array}{l}<10 \% \text { of } \\
\text { tubule } \\
\text { formation } \\
\text { SCORE } 3\end{array}$ & $\begin{array}{c}\text { >=12 } \\
\text { mitoses } \\
\text { SCORE } 3\end{array}$ & $\begin{array}{l}\text { High variability in } \\
\text { shape and size, } \\
\text { prominent nucleoli } \\
\text { SCORE } 3\end{array}$ & 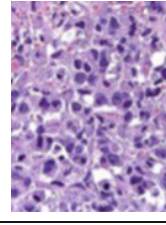 \\
\hline
\end{tabular}

Score 3, 4, 5: G1

Score 6, 7: G2

Score 8, 9: G3

Three parameters are assessed: evaluation of tubule formation, number of mitosis, and nuclear pleomorphism (the latter corresponding to nuclear grade) Scores attributed to single parameters are summed up, and the fi nal score labels the lesion as G1 (low grade), G2 (intermediate grade), or G3 (high grade) * Mitotic count depends on the diameter of the 
microscopic field of the microscope used to analyze the tissue specimen, in the figure we reported values orresponding to $0.46 \mathrm{~mm}$

With respect to nuclear grade, the seminal work by Elston and Ellis ${ }^{32}$ grades nuclear pleomorphism by using three score values. These score values are given by comparing tumor nuclei with nuclei of normal breast, and at least four features are considered: size, shape, uniformity of nuclear chromatin, and nucleoli. Score 1 nuclei are little larger but very similar to normal cell nuclei, while score 3 nuclei show marked variation in size and a "bizarre" morphology. Yet, as noted above with PTC, light microscopy appreciation of foldings and indentations of the nuclear membrane is rough and indirect, being based on the staining of membrane-bound chromatin. Based on these premises it is not surprising that systematic differences between pathologists in scoring nuclear pleomorphism in breast cancer potentially contribute to differences in allocating cases to the correct grade, and the observed discrepancies confirm the need for improved nuclear grading criteria ${ }^{35}, 36$.

Despite their considerable biological interest, the intranuclear tubular extensions of the NE have not gained much attention in pathology. We have therefore endeavoured to investigate whether direct observation of the NE could provide a more objective and direct appreciation of nuclear pleomorphism of breast cancer cells with the fi nal aim to ameliorate definition of prognosis in breast cancer diagnostic pathology.

First, we have carried out a project in which various cell lines (primary cultures of normal mammary epithelium and established breast cancer cell lines) in addition to isolated cells and tissue sections from primary human breast cancer of different grades and stages were examined. Finally, the degree of pleomorphism of the NE was extended to other pathological parameters (histological grade, number of metastatic lymph nodes, vascular invasion, staging) in a series of 273 breast cancers.

Results with in vitro-immortalized cultures showed that nuclei of "normal" breast epithelium when put into 2D cultures displayed a uniformly smooth silhouette, while lamin B and emerin patterns in most breast cancer cell lines resulted to build up, upon 3D reconstruction, a complex scaffold of intranuclear tubular structures (Fig. 6 ). As for tumor cells in human surgical samples, we showed that high nuclear pleomorphism, as defined by staining of the NE proteins emerin and lamin (Fig. 3 ), may potentially recognize within the histologically low-grade cancer group (G1) and in tumors with low proliferation activity, those more prone to metastasize ${ }^{37}$.

Basically, from a practical standpoint, decoration/staining of the NE may be regarded as a novel diagnostic and prognostic parameter that may complement information obtained by conventional cytohistological techniques, and it can be postulated that fi ne detection of the nuclear shape and pleomorphism of the NE represents a novel parameter of interest in pathological grading, holding also a potential impact for planning therapy in breast cancer. Although the significance of this complex scaffold of intranuclear tubular structures is presently unknown it can be hypothesized that irregularities and intranuclear tubules might be involved in or reactive to defects in the nuclearcytoplasmic transport, reportedly a feature typical of cancer cells ${ }^{38}$.

As an additional remark, we have also investigated the possibility to visualize the spatial organization of gene signals with respect to the NE. This can be achieved by coupling immunofluorescence for lamins (or other NE proteins) and FISH for target genes. In particular, for breast cancer we have investigated HER2 gene amplification in BT-474 breast carcinoma cells (Fig. 4 ). HER2 gene amplifi cation is found in about $15-20 \%$ of all breast carcinomas and 
represents the main mechanism driving HER2 activation in breast cancer, which has a negative prognostic impact ${ }^{33},{ }^{39}$. Proper documentation of the presence of HER2 gene amplification represents the crucial step to deliver a specific target therapy in breast carcinoma patients (the humanized antibody trastuzumab, i.e., Herceptin R ${ }^{33}$. This is performed routinely by using an in situ technique, i.e.,FISH, with specific probes directed against the target gene, on sections of human tissue samples. Usually a dual-color probe (one for the gene, the other for the centromere of the chromosome 17 (CEP17), the chromosome where HER2 maps to) is employed, and results can be scored either based on HER2 /CEP17 ratio ( HER2/ CEP17 $\geq 2=$ amplification ) or on the basis of the absolute numbers of the HER2 gene (amplification whenever HER2 > 6) ${ }^{39},{ }^{40}$. For the sake of etection of amplification, only numerical count of signals is performed and no attention is currently paid to the spatial organization of signals.

With our immune-FISH followed by 3D reconstruction we showed in HER2-amplifi ed breast cancer cells a range of patterns in the spatial distribution of gene signals (both single and clustered) with respect to the NE, some being anchored to the NE and others haphazardly spaced within the nucleus. Implications of the relationship between amplified regions of the genome and anchorage to the NE are unknown at present, but it is generally thought that interactions demonstrated between NE proteins and epigenetic heterochromatin marks would correlate peripheral localization with silencing. Nonetheless, further experimental studies would be warranted to properly investigate the implications in terms of activation or inactivation of genes. Indeed, the spatial localization of chromatin within the mammalian nucleus has been shown to be important for several genomic processes ${ }^{41}$, including transcription ${ }^{42}$, RNA processing ${ }^{43}$, as well as DNA repair and recombination ${ }^{44}$. In addition, studies based on 3D-immuno-FISH suggest a key function for the inner nuclear membrane-lamina compartment in transcriptional silencing of large segments of the genome ${ }^{41}$. Finally, very recently it has been demonstrated that the yeast nuclear pore complex protein Nup170p interacts with regions of the genome that contain ribosomal protein and subtle omeric genes, where it functions as a repressor of transcription ${ }^{45}$. These results suggest that nuclear pore proteins areactive participants in silencing and the formation of peripheral heterochromatin ${ }^{45}$.

\section{Conclusions}

Variation in both nuclear shape and size ("pleomorphism"), coupled with changes in chromatin amount and distribution, remains the basic microscopy criteria for a cytologic diagnosis of cancer. The biological determinants of nuclear shape irregularities are not clarified. It has been suggested that alterations in nuclear shape might be related to genetic imbalances in cancer ${ }^{46}$, and Fischer ${ }^{17}$ gave experimental evidence using in vitro models of PTC that induced gene mutations are associated with the structural features typical of this type of thyroid carcinoma that involve rearrangement of the NE and chromatin distribution ${ }^{16},{ }^{17}, 47$. On the other hand, some diseases characterized by genetically determined abnormalities in lamin proteins ${ }^{48},{ }^{49}$ suggest that irregularities in nuclear shape are due to the abnormal farnesylation of lamin proteins, perhaps through interaction of the farnesylated lamins with the phospholipid bilayer ${ }^{50}$. This raises the possibility that both genetic and posttranslational events might be involved in the origin of nuclear shape abnormalities.

Indeed, small GTPases appear to represent a candidate for playing a central role in this process, since they are important in the nuclear envelope assembly ${ }^{51}$ and are notoriously a key player in oncogenesis ${ }^{52},{ }^{53}$. Moreover, recent evidence has been presented ${ }^{54}$ suggesting that prenylation of small GTPases is impaired in cancer cells.

Other reviews focus on possible mechanisms to generate nuclear shape abnormalities, but here we focus on using these diagnostically. Standard H\&E staining cannot adequately distinguish fi ne abnormalities of the nuclear shape, as it is indirectly based on the distribution of DNA as revealed by the affinity for basic dyes.

A more objective definition of the shape of the nucleus can be provided by decoration/staining of the NE, followed by image capture and 3D reconstruction. We applied this approach to two areas of tumor pathology: thyroid and breast cancer. In the papillary type of thyroid cancer, most nuclei show a variation in shape so typical as to be paradigmatic and diagnostic, while in breast cancer 
nuclear irregularities vary according to the subtype and the aggressiveness of cancer. For instance it is minimal in tubular carcinoma while marked in grade 3 cancers.

The technical approach presented here proved feasible on both isolated cells and tissue sections and ultimately provides a reproducible approach of diagnostic and clinical interest.

The pathological diagnosis of PTC is usually straightforward since the majority of cases of PTC are easy to diagnose on routine-stained preparations, with overt irregularities, such as grooves, pseudo-inclusions, and ground-glass appearance.

Although these nuclear changes help to defi ne PTC, these features are only diagnostic when widespread and in combination. However, in some cases both in histology and cytology diagnosis of PTC can be challenging, and the classical microscope observation of PTC nuclei (based on nucleic acid staining with basic dyes, such as hematoxylin) is clearly insuffi cient to appreciate the complete spectrum of PTC nuclear irregularities.

By tracing in immunofluorescence and immunoperoxidase proteins of the NE (e.g., lamins, emerin), it is possible to obtain a clear, evident, and direct representation of nuclear shape, thus highlighting those microscopical features barely visible with H\&E.

When shifting the attention from the "content" (chromatin) to the "container" (nuclear membrane), confocal microscopy and 3D reconstructions provided us models of nuclear structure in PTC cells, and emerin immunostaining on cytological and histological samples proved a feasible tool to improve diagnosis in "difficult" PTC cases.

In breast cancer, the presence of an extensive network of invaginated projections of the NE inside the nucleus, as revealed by tagging lamin B and emerin in immunofluorescence preparations, opens prospects of biological and diagnostic interest.

Intranuclear tubules are an interesting and intriguing phenomenon, possibly involved in or reactive to defects in the nuclear-cytoplasmic transport, reportedly a feature typical of cancer cells. In addition, this scaffold might also be a drug target since Lee et al. ${ }^{55}$ already demonstrated a selective binding of doxorubicin to intranuclear tubules. Moreover, the combined 3D detection of the spatial distribution of genes and intranuclear invaginations, as exemplified in the present study, might provide a novel interpretation on active versus inactive genes. Indeed, other studies based on 3D-immuno-FISH seem to suggest the inner nuclear membrane-lamina compartment as a key player in transcriptional silencing of large segments of the genome ${ }^{41}$.

Finally, we gave evidence that immunofluorescence decoration/staining of the NE provides a reproducible and objective evaluation of nuclear shape irregularities associated with pleomorphism and provides prognostic information to parallel and enhance that provided by routine histological procedures.

Acknowledgements GB is funded by Persother (SMIS-CSRN:549/12.024); AS is funded by AIRC (IG10787) and Ricerca Sanitaria Finalizzata (RF-2010-2310674); and CM is funded by AIRC (MFAG 13310).

\section{References}

1. Bussolati G (2008) Proper detection of the nuclear shape: ways and signifi cance. Rom J Morphol Embryol 49(4):435-439, 490408435439 [pii]

2. Ghadially F (1988) Ultrastructural pathology of the cell and matrix: a text and atlas of physiological and pathological alterations in the fine structure of cellular and extracellular components, vol 1, 3rd edn. Butterworths, London

3. Frost $J(1986)$ The cell in health and disease: an evaluation of cellular morphologic expression of biologic behavior. Karger, Basel, 2nd revised edn

4. Johannessen JV, Gould VE, Jao W (1978) The fine structure of human thyroid cancer. Hum Pathol 9(4):385-400 
5. Batistatou A, Scopa CD (2009) Pathogenesis and diagnostic significance of nuclear grooves in thyroid and other sites. Int J Surg Pathol 17(2):107-110. doi: 10.1177/1066896908316071, 1066896908316071 [pii]

6. LiVolsi VA (2011) Papillary thyroid carcinoma: an update. Mod Pathol 24(Suppl 2):S1-S9. doi: 10.1038/modpathol.2010.129, modpathol2010129 [pii]

7. Arora SK, Dey P (2012) Intranuclear pseudoinclusions: morphology, pathogenesis, and signifi cance. Diagn Cytopathol 40(8):741-744. doi: 10.1002/dc.21714

8. Cancer TIAfRo (2004) Pathology and genetics of tumours of endocrine organs (IARC WHO classifi cation of tumours), 1st edn. IARC Press, Lyon

9. Asioli S, Bussolati G (2009) Emerin immunohistochemistry reveals diagnostic features of nuclear membrane arrangement in thyroid lesions. Histopathology 54(5):571-579.

doi: 10.1111/j.1365-2559.2009.03259.x , HIS3259 [pii]

10. Papotti M, Manazza AD, Chiarle R, Bussolati G (2004) Confocal microscope analysis and tridimensional reconstruction of papillary thyroid carcinoma nuclei. Virchows Arch 444(4):350-355. doi: 10.1007/s00428-003-0962-4

11. Holmes TJ (1992) Blind deconvolution of quantum-limited incoherent imagery: maximumlikelihood approach. J Opt Soc Am A 9(7):1052-1061

12. Holmes TJ, O'Connor NJ (2000) Blind deconvolution of 3D transmitted light brightfi eld micrographs. J Microsc 200(Pt 2):114-127, jmi751 [pii]

13. Baloch ZW, LiVolsi VA (2002) Etiology and signifi cance of the optically clear nucleus. Endocr Pathol 13(4):289-299, EP:13:4:289 [pii]

14. Asioli S, Maletta F, Pacchioni D, Lupo R, Bussolati G (2010) Cytological detection of papillary thyroid carcinomas by nuclear membrane decoration with emerin staining. Virchows Arch 457(1):43-51. doi: 10.1007/s00428-010-0910-z

15. Kinsella MD, Hinrichs B, Cohen C, Siddiqui MT (2012) Highlighting nuclear membrane staining in thyroid neoplasms with emerin: review and diagnostic utility. Diagn Cytopathol 41(6):497-504. doi: 10.1002/dc.22870

16. Fischer AH, Taysavang $P$, Weber CJ, Wilson KL (2001) Nuclear envelope organization in papillary thyroid carcinoma. Histol Histopathol 16(1):1-14

17. Fischer AH, Taysavang P, Jhiang SM (2003) Nuclear envelope irregularity is induced by RET/ PTC during interphase. Am J Pathol 163(3):1091-1100

18. Bell CD, Coire C, Treger T, Volpe R, Baumal R, Fornasier VL (2001) The 'dark nucleus' and disruptions of follicular architecture: possible new histological aids for the diagnosis of the follicular variant of papillary carcinoma of the thyroid. Histopathology 39(1):33-42, his1137 [pii]

19. Liu J, Singh B, Tallini G, Carlson DL, Katabi N, Shaha A, Tuttle RM, Ghossein RA (2006) Follicular variant of papillary thyroid carcinoma: a clinicopathologic study of a problematic entity. Cancer 107(6):1255-1264. doi: 10.1002/cncr.22138

20. Chan J (2002) Strict criteria should be applied in the diagnosis of encapsulated follicular variant of papillary thyroid carcinoma. Am J Clin Pathol 117(1):16-18. doi: 10.1309/

P7QL-16KQ-QLF4-XWOM 
21. Lloyd RV, Erickson LA, Casey MB, Lam KY, Lohse CM, Asa SL, Chan JK, DeLellis RA, Harach HR, Kakudo K, LiVolsi VA, Rosai J, Sebo TJ, Sobrinho-Simoes M, Wenig BM, Lae ME (2004) Observer variation in the diagnosis of follicular variant of papillary thyroid carcinoma. Am J Surg Pathol 28(10):1336-1340, 00000478-200410000-00009 [pii]

22. Suster $S$ (2006) Thyroid tumors with a follicular growth pattern: problems in differential diagnosis. Arch Pathol Lab Med 130(7):984-988. doi: 10.1043/1543-2165(2006) 130[984:TTWAFG]2.0.CO;2 , 2006-0069-RAR [pii]

23. Volante M, Collini P, Nikiforov YE, Sakamoto A, Kakudo K, Katoh R, Lloyd RV, LiVolsi VA, Papotti M, Sobrinho-Simoes M, Bussolati G, Rosai J (2007) Poorly differentiated thyroid carcinoma: the Turin proposal for the use of uniform diagnostic criteria and an algorithmic diagnostic approach. Am J Surg Pathol 31(8):1256-1264. doi: 10.1097/PAS.0b013e3180309e6a , 00000478-200708000-00017 [pii]

24. Cibas ES, Ali SZ (2009) The Bethesda System For Reporting Thyroid Cytopathology. Am J Clin Pathol 132(5):658-665. doi: 10.1309/AJCPPHLWMI3JV4LA , 132/5/658 [pii]

25. Baloch ZW, Fleisher S, LiVolsi VA, Gupta PK (2002) Diagnosis of "follicular neoplasm": a gray zone in thyroid fi ne-needle aspiration cytology. Diagn Cytopathol 26(1):41-44, 10.1002/ dc.10043 [pii]

26. Baloch ZW, Sack MJ, Yu GH, Livolsi VA, Gupta PK (1998) Fine-needle aspiration of thyroid: an institutional experience. Thyroid 8(7):565-569

27. Gharib H (1994) Fine-needle aspiration biopsy of thyroid nodules: advantages, limitations, and effect. Mayo Clin Proc 69(1):44-49

28. Asa SL (2005) The role of immunohistochemical markers in the diagnosis of follicularpatterned lesions of the thyroid. Endocr Pathol 16(4):295-309, EP:16:4:295 [pii]

29. Papotti M, Rodriguez J, De Pompa R, Bartolazzi A, Rosai J (2005) Galectin-3 and HBME-1 expression in well-differentiated thyroid tumors with follicular architecture of uncertain malignant potential. Mod Pathol 18(4):541-546. doi: 10.1038/modpathol.3800321 , 3800321 [pii]

30. Bartolazzi A, Orlandi F, Saggiorato E, Volante M, Arecco F, Rossetto R, Palestini N, Ghigo E, Papotti M, Bussolati G, Martegani MP, Pantellini F, Carpi A, Giovagnoli MR, Monti S, Toscano V, Sciacchitano S, Pennelli GM, Mian C, Pelizzo MR, Rugge M, Troncone G, Palombini L, Chiappetta G, Botti G, Vecchione A, Bellocco R (2008) Galectin-3-expression analysis in the surgical selection of follicular thyroid nodules with indeterminate fi ne-needle aspiration cytology: a prospective multicentre study. Lancet Oncol 9(6):543-549. doi: 10.1016/S1470-2045(08)70132-3 , S14702045(08)70132-3 [pii

31. Saggiorato E, De Pompa R, Volante M, Cappia S, Arecco F, Dei Tos AP, Orlandi F, Papotti M (2005) Characterization of thyroid 'follicular neoplasms' in fi ne-needle aspiration cytological specimens using a panel of immunohistochemical markers: a proposal for clinical application. Endocr Relat Cancer 12(2):305-317. doi: 10.1677/erc.1.00944 , 12/2/305 [pii]

32. Elston CW, Ellis IO (1991) Pathological prognostic factors in breast cancer. I. The value of histological grade in breast cancer: experience from a large study with long-term follow-up. Histopathology 19(5):403-410

33. Marchio C, Reis-Filho JS (2008) Molecular diagnosis in breast cancer. Diagn Histopatho 14:5

34. Robbins P, Pinder S, de Klerk N, Dawkins H, Harvey J, Sterrett G, Ellis I, Elston C (1995) 
Histological grading of breast carcinomas: a study of interobserver agreement. Hum Pathol 26(8):873-879

35. Meyer JS, Alvarez C, Milikowski C, Olson N, Russo I, Russo J, Glass A, Zehnbauer BA, Lister K, Parwaresch R (2005) Breast carcinoma malignancy grading by Bloom-Richardson system vs proliferation index: reproducibility of grade and advantages of proliferation index. Mod Pathol 18(8):1067-1078. doi: 10.1038/modpathol.3800388 , 3800388 [pii]

36. Sloane JP, Amendoeira I, Apostolikas N, Bellocq JP, Bianchi S, Boecker W, Bussolati G, Coleman D, Connolly CE, Eusebi V, De Miguel C, Dervan P, Drijkoningen R, Elston CW, Faverly D, Gad A, Jacquemier J, Lacerda M, Martinez-Penuela J, Munt C, Peterse JL, Rank F, Sylvan M, Tsakraklides V, Zafrani B (1999) Consistency achieved by 23 European pathologists from 12 countries in diagnosing breast disease and reporting prognostic features of carcinomas. European Commission Working Group on Breast Screening Pathology. Virchows Arch 434(1):3-10

37. Bussolati G, Marchio C, Gaetano L, Lupo R, Sapino A (2008) Pleomorphism of the nuclear envelope in breast cancer: a new approach to an old problem. J Cell Mol Med 12(1):209-218. doi: 10.1111/j.1582-4934.2007.00176.x , JCMM176 [pii]

38. Kau TR, Way JC, Silver PA (2004) Nuclear transport and cancer: from mechanism to intervention. Nat Rev Cancer 4(2):106-117. doi: 10.1038/nrc1274 , nrc1274 [pii]

39. Sapino A, Goia M, Recupero D, Marchio C (2013) Current challenges for HER2 testing in diagnostic pathology: state of the art and controversial issues. Front Oncol 3:129. doi: 10.3389/fonc.2013.00129 40. Wolff AC, Hammond ME, Hicks DG, Dowsett M, McShane LM, Allison KH, Allred DC, Bartlett JM, Bilous M, Fitzgibbons P, Hanna W, Jenkins RB, Mangu PB, Paik S, Perez EA, Press MF, Spears PA, Vance GH, Viale G, Hayes DF; American Society of Clinical Oncology; College of American Pathologists (2013) Recommendations for human epidermal growth factor receptor 2 testing in breast cancer: American Society of Clinical Oncology/College of American Pathologists clinical practice guideline update. J Clin Oncol. 2013;31(31):3997-4013. doi: 10.1200/JCO.2013.50.9984. Epub 2013 Oct 7

41. Zullo JM, Demarco IA, Pique-Regi R, Gaffney DJ, Epstein CB, Spooner CJ, Luperchio TR, Bernstein BE, Pritchard JK, Reddy KL, Singh H (2012) DNA sequence-dependent compartmentalization and silencing of chromatin at the nuclear lamina. Cell 149(7):1474-1487. doi: 10.1016/j.cell.2012.04.035 , S0092-8674(12)00591-0 [pii]

42. Sutherland $\mathrm{H}$, Bickmore WA (2009) Transcription factories: gene expression in unions? Nat Rev Genet 10(7):457-466. doi: 10.1038/nrg2592, nrg2592 [pii]

43. Lamond Al, Spector DL (2003) Nuclear speckles: a model for nuclear organelles. Nat Rev Mol Cell Biol 4(8):605-612. doi: 10.1038/nrm1172, nrm1172 [pii]

44. Misteli T, Soutoglou E (2009) The emerging role of nuclear architecture in DNA repair and genome maintenance. Nat Rev Mol Cell Biol 10(4):243-254. doi: 10.1038/nrm2651, nrm2651 [pii]

45. Van de Vosse DW, Wan Y, Lapetina DL, Chen WM, Chiang JH, Aitchison JD, Wozniak RW (2013) A role for the nucleoporin Nup170p in chromatin structure and gene silencing. Cell 152(5):969-983. doi: 10.1016/j.cell.2013.01.049 , S0092-8674(13)00141-4 [pii]

46. Fischer AH, Zhao C, Li QK, Gustafson KS, Eltoum IE, Tambouret R, Benstein B, Savaloja LC, Kulesza P (2010) The cytologic criteria of malignancy. J Cell Biochem 110(4):795-811. doi: $10.1002 / j c b .22585$

47. Fischer AH, Bond JA, Taysavang P, Battles OE, Wynford-Thomas D (1998) Papillary thyroid 
carcinoma oncogene (RET/PTC) alters the nuclear envelope and chromatin structure. Am J Pathol 153(5):1443-1450

48. Eriksson M, Brown WT, Gordon LB, Glynn MW, Singer J, Scott L, Erdos MR, Robbins CM, Moses TY, Berglund P, Dutra A, Pak E, Durkin S, Csoka AB, Boehnke M, Glover TW, Collins FS (2003) Recurrent de novo point mutations in lamin A cause Hutchinson-Gilford progeria syndrome. Nature 423(6937):293-298. doi: 10.1038/nature01629, nature01629 [pii]

49. Maraldi NM, Lattanzi G, Capanni C, Columbaro M, Merlini L, Mattioli E, Sabatelli P, Squarzoni S, Manzoli FA (2006) Nuclear envelope proteins and chromatin arrangement: a pathogenic mechanism for laminopathies. Eur J Histochem 50(1):1-8

50. Polychronidou M, Grobhans J (2011) Determining nuclear shape: the role of farnesylated nuclear membrane proteins. Nucleus 2(1):17-23. doi: 10.4161/nucl.2.1.13992 , 1949-1034-2- 1-4 [pii]

51. Hetzer M, Gruss OJ, Mattaj IW (2002) The Ran GTPase as a marker of chromosome position in spindle formation and nuclear envelope assembly. Nat Cell Biol 4(7):E177-E184.

doi: 10.1038/ncb0702-e177, ncb0702-e177 [pii]

52. Bendris N, Arsic N, Lemmers B, Blanchard JM (2012) Cyclin A2, Rho GTPases and EMT. Small GTPases 3(4):225-228. doi: 10.4161/sgtp.20791 , 20791 [pii]

53. Recchi C, Seabra MC (2012) Novel functions for Rab GTPases in multiple aspects of tumour progression. Biochem Soc Trans 40(6):1398-1403. doi: 10.1042/BST20120199 , BST20120199 [pii]

54. Ntantie E, Gonyo P, Lorimer EL, Hauser AD, Schuld N, McAllister D, Kalyanaraman B, Dwinell MB, Auchampach JA, Williams CL (2013) An adenosine-mediated signaling pathway suppresses prenylation of the GTPase Rap1B and promotes cell scattering. Sci Signal 6(277):ra39. doi: 10.1126/scisignal.2003374 , 6/277/ra39 [pii]

55. Lee RK, Lui PP, Ngan EK, Lui JC, Suen YK, Chan F, Kong SK (2006) The nuclear tubular invaginations are dynamic structures inside the nucleus of HeLa cells. Can J Physiol Pharmacol 84(3-4):477-486. doi: 10.1139/y05-110 , y05-110 [pii] 